\title{
Performance Tests of Three Types of Air-sampling Bags on Organic Solvent Vapor Retention
}

\author{
Yoshinari FUKUI ${ }^{1}$, Ai KANEMARU ${ }^{1}$, Yasuhiro NAGASAWA ${ }^{1}$, Takuya KAWAKAMI ${ }^{1}$, \\ Toyoto IWATA ${ }^{2}$, Katsuyuki MURATA ${ }^{2}$, Fumiko OHASHI ${ }^{1}$ and Masayuki IKEDA ${ }^{1}$ * \\ ${ }^{1}$ Kyoto Industrial Health Association (Main Office), Japan \\ ${ }^{2}$ Department of Environmental Health Sciences, Akita University Graduate School of Medicine, Japan
}

Received September 21, 2012 and accepted November 29, 2012

Published online in J-STAGE February 4, 2013

\begin{abstract}
Performance of two new air sampling bags [the transparent bag (TP bag) and the semitransparent bag (ST bag)] was examined as possible surrogates for the traditional PVF bag (the Ref bag). Solvent vapor mixture of butyl acetate, chloroform, ethyl acetate, isopropyl alcohol and toluene at administrative control levels were introduced to each bag ( $n=5$ for each of the three types), and the decay in the concentrations (by\%) was followed by use of a gas auto-sampler - FID-GC system. A trend of time-dependent decay was noted for all types including the Ref bag. When the performance was compared, the TP bag was equal to or even better than the Ref bag. In contrast, the performance of the ST bag was comparable to that of the other two types of bags with regard to toluene and chloroform when the storage time was short, but poorer than others for the other three solvents throughout the test period. The TP bag may be a bag of choice when the storage time is extended (e.g., up to $48 \mathrm{~h}$ ) although this bag is physically less robust and requires careful handling. The ST bag may be used when analysis will be completed within $24 \mathrm{~h}$.
\end{abstract}

Key words: Air sampling bag, Decay by time, Organic solvents, Retention rate

Air sampling bags made of polyvinyl fluoride (PVF; e.g., Tedlar ${ }^{\circledR}$ bag) have been employed for years for air sampling of chemical substances, typically organic solvents, because of good performance in retaining chemical vapors. Nevertheless, a shortage of the supply due to economic reasons makes it urgently necessary to find any proper surrogate bag products for sampling.

The present study was initiated to examine three commercially available products for their performance of retaining organic solvent vapors. The two types of bags other than the PVF bag were chosen for performance test as they are most readily available currently on a commercial basis and therefore assumedly with high popularity.

*To whom correspondence should be addressed.

E-mail: ikeda@hokenkai.jp

(C)2013 National Institute of Occupational Safety and Health
In this study, the suitability of the two new bags is evaluated on the basis of the test for retention performance. The choice of the two bags depending on the application conditions (e.g., expected duration of storage) will also be proposed in the present report.

Three types of bags (10-1) were examined. The first one (50 $\mu \mathrm{m}$ in thickness) was made of PVF. This type of the bag was called the reference bag (or Ref bag in short) as this type of bag has been in use for a long time, and will be examined in the present study as a reference in performance. The second one, a newly supplied product, was made of polyvinyl terephthalate (fortified; $45 \mathrm{~mm}$ in thickness). This bag was transparent and rough to the touch (to be called the TP bag). The third bag, also a new product, was made of polyvinylidene fluoride $(50 \mathrm{~mm}$ in thickness), and was semi-transparent and soft to the touch (to be called the ST bag). Five organic solvents (target 
concentrations in parentheses) of $n$-butyl acetate (150 ppm), chloroform (3 ppm), ethyl acetate (200 ppm), isopropyl alcohol (200 ppm), and toluene (20 ppm) were selected for testing; they were chosen because of popular use in industrial settings ${ }^{1)}$ except for chloroform which is an important solvent in research laboratories ${ }^{2}$. The target concentrations were set at the administrative control level ${ }^{3)}$.

Under chromatographic conditions employed (for details, see below), it was not possible to achieve clear separation between ethyl acetate and isopropyl alcohol (also see Chromatogram 1 and Chromatogram 2 in Fig. 1). Thus, the five solvents were tested in two groups. Toluene $(0.3 \mathrm{ml})$ and ethyl acetate $(2.3 \mathrm{ml})$ were dissolved in $50 \mathrm{ml}$ methyl alcohol (Solution 1) and subjected to Group 1 testing, and chloroform $(0.1 \mathrm{ml})$, isopropyl alcohol $(3.7 \mathrm{ml})$ and butyl acetate $(6.0 \mathrm{ml})$ were dissolved in another $50 \mathrm{ml}$ methyl alcohol (Solution 2) for Group 2 testing. Solution $1(200 \mu \mathrm{l})$ and Solution $2(100 \mu \mathrm{l})$ were introduced into individual 5 bags of the three types (for the Group 1 and Group 2 test, respectively) to generate solvent vapors at desired concentrations.

Thus, 30 bags ( 5 bags each of 3 types of bags for two groups) in total were subjected to the testing. After closing the inlet and confirming complete evaporation of the injected solution, the solvent vapor-loaded air in the bag was mixed well by gentle pressing from outside of the bag in diverse directions to force the air inside to move around for about $5 \mathrm{~min}$ after the injection.

The system was a combination of a gas auto-sampler (CORE Corp., Hiroshima, Japan) and a flame ionization detector-gaschromatograph (FID-GC; Shimadzu GC2014AFSPL). The GC was equipped with $3.1 \mathrm{~m}$-long $(\varphi=3.2 \mathrm{~mm})$ SBS-120 SHINCARBON A (80/100) column, which was kept at $100^{\circ} \mathrm{C} . \mathrm{N}_{2}$ gas was allowed to flow at $30 \mathrm{ml} / \mathrm{min}$. Sample air $(2 \mathrm{ml})$ was introduced to the system after replacement of dead-space air in the gas auto-sampler by about $100 \mathrm{ml}$ sample air at $0,12,24,36$ and $48 \mathrm{~h}$; the sampling was terminated at $48 \mathrm{~h}$ because it is the practice of this laboratory to finish air analyses within $48 \mathrm{~h}$. The retention times (in the order of appearance) for isopropyl alcohol, ethyl acetate, chloroform, toluene and butyl acetate were $2.3,2.9,4.4,7.8$, and 8.8 min after injection, respectively. Two typical chromatograms, one each for Group 1 and Group 2 analysis, are depicted in Fig. 1 to show clear separation of peaks.

The quality of analyses for organic solvents were certified (valid from 1 April, 2012 to 31 March, 2014) in the 5 th quality assurance program by Japan Association for Working Environment Measurement, Tokyo, Japan.
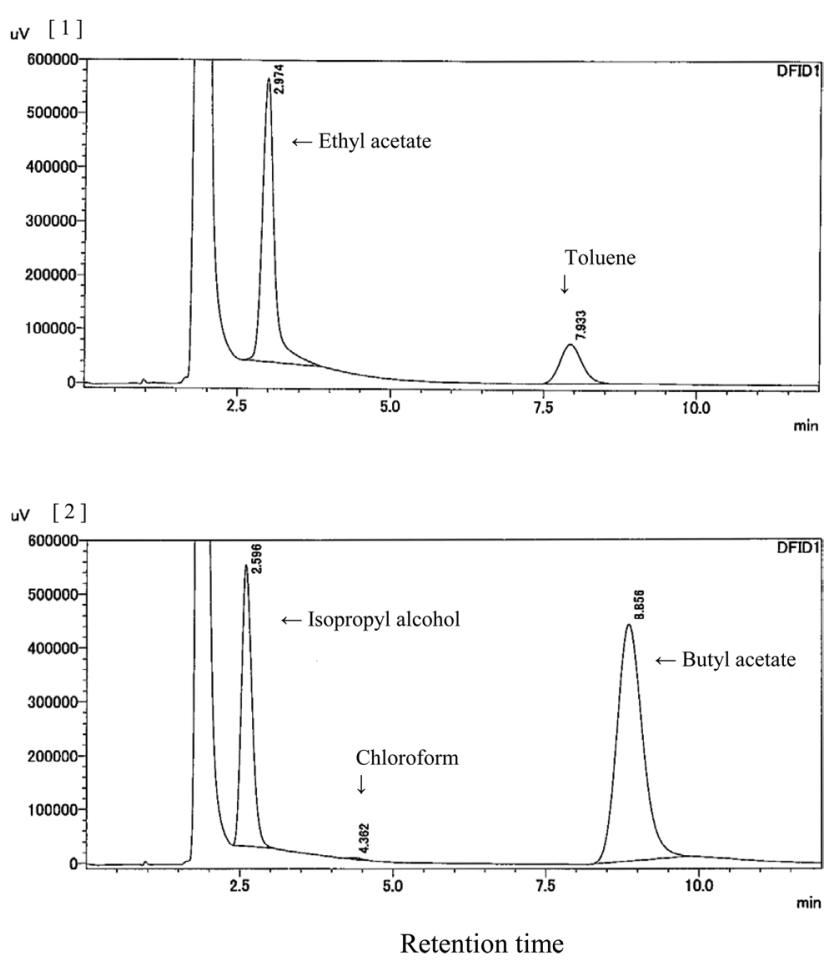

Fig. 1. Typical chromatograms to show separation of the tested organic solvents.

Chromatogram 1 is for Group 1 solvents, and Chromatogram 2 is for Group 2 solvents. In Chromatogram 2, the peak for chloroform is small due to the low test concentration (i.e., $3 \mathrm{ppm}$ ), and the location is indicated by an arrow with the retention time. The left-most large peak in each chromatogram (with a retention time of about $2 \mathrm{~min}$ ) is for methyl alcohol, the diluent.

A statistical software, StataSE 11.2 for Windows (StataCorp, TX, USA), was employed, and $p<0.05$ was taken as a cut-off for detection of significant differences. For analysis of time trends of decrease in vapor concentration in each type of bag, one-way repeated measures analysis of variance (ANOVA) was conducted and the significance of differences between the $0 \mathrm{~h}$ value and the other ones was analyzed by the Bonferroni multiple comparison method. In addition, two-way repeated measures ANOVA was applied with Greenhouse-Geisser adjustment and Bonferroni multiple comparison to isolate differences among three types of bags.

The measured values were presented as percentages taking 0 -h value as 100 , and are presented in terms of arithmetic means (AMs) and arithmetic standard deviations (ASDs) of the percentages in Table 1. In evaluation, possible difference in retention of the solvents was examined by ANOVA in each type of the bags, i.e., the Ref bag, the TP bag or the ST bag at different time of sampling; 
only possible difference from 0 -h values are presented in the table.

There was a general trend of time-dependent decrease irrespective of the types of bags. It should also be noted that the coefficients of variation (the rates of ASD to corresponding $\mathrm{AM}$ ) was $<1 \%$ in most cases, but was up to $6.1 \%$ in cases of chloroform possibly due to limitation in experimental conditions as to be described later.

To compare the retention performance among the three types of bags, ANOVA with Greenhouse-Geisser adjustment was applied (Table 2). It was clear that $p$-values were $<0.05$ irrespective of five solvents tested, indicating that the performance differed significantly among the three types of bags. Further comparisons between two types of bags among the three revealed that the performance of the TP bag was either equal to or even better than that of the Ref bag across the five solvents throughout the duration of storage up to $48 \mathrm{~h}$. In contrast, the performance of the ST bag was comparable to that of the Ref bag and of the TP bag with regard to toluene and chloroform especially when the storage duration was short, but poorer than other two bags in cases of other three solvents throughout the test period.

For semi-quantitative evaluation, $95 \%$ retention was tentatively taken as a cut-off. The Ref bag could retain $>95 \%$ of butyl acetate for $12 \mathrm{~h}$, toluene for $24 \mathrm{~h}$, ethyl acetate for $36 \mathrm{~h}$, and isopropyl alcohol and chloroform for $>48 \mathrm{~h}$. In case of the TP bag, retention was $>95 \%$ of chloroform for $24 \mathrm{~h}$ and $>48 \mathrm{~h}$ in cases of other four solvents. The ST bag could retain $>95 \%$ of butyl acetate for $<12 \mathrm{~h}$, ethyl acetate, toluene, and isopropyl alcohol for $12 \mathrm{~h}$, and chloroform for $>48 \mathrm{~h}$.

Several factors should be taken into consideration in evaluating performance (typically solvent vapor retention) of air sampling bags as a tool to collect samples containing organic solvent vapors, i.e., 1. materials of the bags, 2 . film thickness, 3. bag size, 4. type of organic solvents to be examined, 5. expected duration of storage prior to the GC analysis, and 6. fragility and robustness for repeated use ${ }^{4-15}$. With regard to bag size (or the amount of air to be sampled), 10-1 bags were employed in the present study. Improvement in retention was reported as a function of increasing sizes of bags with a plateau at $8-121$ in the size ${ }^{8-10)}$. From the present observation (Table 1), acetate esters (such as ethyl acetate and n-butyl acetate) tended to be lost more quickly than others (e.g., toluene). In addition, a low retention was found for methyl alcohol ${ }^{15)}$, although retention rate was not poor for isopropyl alcohol (Table 1) or 1-butyl alcohol ${ }^{15)}$. Thus, acetate esters and methyl alcohol would be the sol- vents of choice for testing retention performance. With this regard, vapor concentration may not affect retention rate. For example, the retention of toluene in 10-1 PVF bags at $48 \mathrm{~h}$ of storage was $92 \%$ when the initial concentration was $20 \mathrm{ppm}$ (Table 1), whereas it was $93 \%$ for toluene at $0.1 \mathrm{ppm}^{6}$. For time-dependent decay in the concentration, experiment-based adjustment equations were proposed to deal with the concentration reduction ${ }^{7,11)}$. In the present analysis, this approach was not considered practical because the decay curves were different among solvents so that the correction equations were also solvent-specific. Rather, a better retention rate of $>95 \%$ was considered as selection criterion. Empirically, toughness of the bags in terms of break-resistance and tolerance for repeated use is of practical importance.

The observation that the coefficients of variation tended to be large for chloroform (3 to $6 \%$ across three types of bags; Table 1) may deserve attention. This is primarily due to the fact that the concentration for chloroform loaded in bags was as low as $3 \mathrm{ppm}$ (whereas it was 20 to $200 \mathrm{ppm}$ for other four solvents). In addition, it is known that flame-ionization detectors are less sensitive for chloroform than for others e.g. toluene. Thus, under the analytical conditions employed, the results for chloroform might be less reliable than those for ethyl acetate, toluene, isopropyl alcohol and butyl acetate.

Taking all factors together, the TP bag would be the bag of choice when it is necessary to store the samples for up to $48 \mathrm{~h}$, e.g., sampling on Friday and analysis on Monday of the next week even though careful handling of the bags is necessary in precaution of breakage. The ST bag can also be employed (with need of less care in handling) when GC analysis can be completed within $24 \mathrm{~h}$ after sampling, e.g., when the conditions permit over-night operation of the gas auto-sampler - FID-GC complex.

Overall, the present testing disclosed that the Ref bag, which had been used traditionally for years, may lose more than $5 \%$ of some solvents in 24 to $48 \mathrm{~h}$, whereas the TP bag could retain almost all solvents tested without significant loss. Loss was most substantial for the ST bag. Experience of use however showed that the TP bag is physically weak and fragile, and is more readily broken than the other two types of bags.

\section{Acknowledgement}

Thanks are due to the administration and staff of Kyoto Industrial Health Association for their interest in and support to this study. 
Table 1. Comparison of three types of bags regarding time-dependent possible loss of five organic solvents

\begin{tabular}{|c|c|c|c|c|c|c|c|}
\hline \multirow{2}{*}{ Organic solvent } & \multirow{2}{*}{$\mathrm{Bag}^{\mathrm{a}}$} & \multirow{2}{*}{ Parameter } & \multicolumn{5}{|c|}{ Duration of storage (h) } \\
\hline & & & 0 & 12 & 24 & 36 & 48 \\
\hline \multicolumn{8}{|l|}{ Group 1} \\
\hline \multirow[t]{9}{*}{ Ethyl acetate } & Ref & $\mathrm{AM}$ & 100 & 98.7 & 96.7 & 95.6 & 94.1 \\
\hline & & ASD & 0 & 0.3 & 0.5 & 0.7 & 1.1 \\
\hline & & $p^{\mathrm{b}}$ & & $\downarrow$ & $\downarrow$ & $\downarrow$ & $\downarrow$ \\
\hline & $\mathrm{TP}$ & $\mathrm{AM}$ & 100 & 101.9 & 99.1 & 98.4 & 96.6 \\
\hline & & ASD & 0 & 1.2 & 2.1 & 3.3 & 4.3 \\
\hline & & $p^{\mathrm{b}}$ & & ns & $\mathrm{ns}$ & ns & $\mathrm{ns}$ \\
\hline & ST & $\mathrm{AM}$ & 100 & 95.6 & 90.2 & 88.0 & 84.9 \\
\hline & & ASD & 0 & 0.7 & 0.4 & 0.5 & 0.7 \\
\hline & & $p^{\mathrm{b}}$ & & $\downarrow$ & $\downarrow$ & $\downarrow$ & $\downarrow$ \\
\hline \multirow[t]{9}{*}{ Toluene } & Ref & $\mathrm{AM}$ & 100 & 97.7 & 95.3 & 93.5 & 91.6 \\
\hline & & ASD & 0 & 0.5 & 0.5 & 1.0 & 0.9 \\
\hline & & $p^{\mathrm{b}}$ & & $\downarrow$ & $\downarrow$ & $\downarrow$ & $\downarrow$ \\
\hline & $\mathrm{TP}$ & $\mathrm{AM}$ & 100 & 101.2 & 98.2 & 97.0 & 95.5 \\
\hline & & ASD & 0 & 1.7 & 2.3 & 3.5 & 4.3 \\
\hline & & $p^{\mathrm{b}}$ & & ns & ns & ns & $\downarrow$ \\
\hline & ST & $\mathrm{AM}$ & 100 & 99.0 & 94.8 & 92.9 & 90.6 \\
\hline & & ASD & 0 & 0.9 & 0.7 & 1.0 & 1.0 \\
\hline & & $p^{\mathrm{b}}$ & & $\mathrm{ns}$ & $\downarrow$ & $\downarrow$ & $\downarrow$ \\
\hline \multicolumn{8}{|l|}{ Group 2} \\
\hline \multirow[t]{9}{*}{ Isopropyl alcohol } & Ref & $\mathrm{AM}$ & 100 & 98.8 & 97.0 & 97.4 & 95.3 \\
\hline & & ASD & 0 & 0.9 & 1.5 & 1.4 & 1.9 \\
\hline & & $p^{\mathrm{b}}$ & & $\mathrm{ns}$ & $\downarrow$ & $\downarrow$ & $\downarrow$ \\
\hline & $\mathrm{TP}$ & $\mathrm{AM}$ & 100 & 99.1 & 96.7 & 97.0 & 95.6 \\
\hline & & ASD & 0 & 0.6 & 1.4 & 2.2 & 3.6 \\
\hline & & $p^{\mathrm{b}}$ & & ns & $\downarrow$ & $\downarrow$ & $\downarrow$ \\
\hline & ST & $\mathrm{AM}$ & 100 & 95.4 & 93.7 & 94.0 & 92.7 \\
\hline & & ASD & 0 & 1.0 & 0.9 & 1.0 & 1.1 \\
\hline & & $p^{\mathrm{b}}$ & & $\downarrow$ & $\downarrow$ & $\downarrow$ & $\downarrow$ \\
\hline \multirow[t]{9}{*}{ Chloroform } & Ref & $\mathrm{AM}$ & 100 & 100.6 & 98.9 & 97.2 & 96.1 \\
\hline & & ASD & 0 & 3.8 & 4.4 & 6.0 & 4.7 \\
\hline & & $p^{\mathrm{b}}$ & & ns & $\mathrm{ns}$ & ns & $\mathrm{ns}$ \\
\hline & $\mathrm{TP}$ & $\mathrm{AM}$ & 100 & 98.4 & 96.9 & 93.9 & 92.7 \\
\hline & & ASD & 0 & 2.9 & 3.3 & 5.2 & 3.8 \\
\hline & & $p^{\mathrm{b}}$ & & ns & ns & $\downarrow$ & $\downarrow$ \\
\hline & ST & $\mathrm{AM}$ & 100 & 97.8 & 102.2 & 101.7 & 104.5 \\
\hline & & ASD & 0 & 3.5 & 1.3 & 4.2 & 1.5 \\
\hline & & $p^{\mathrm{b}}$ & & ns & ns & ns & ns \\
\hline \multirow[t]{9}{*}{ Butyl acetate } & Ref & $\mathrm{AM}$ & 100 & 98.6 & 94.3 & 94.1 & 90.3 \\
\hline & & ASD & 0 & 0.5 & 0.5 & 0.6 & 0.9 \\
\hline & & $p^{\mathrm{b}}$ & & $\downarrow$ & $\downarrow$ & $\downarrow$ & $\downarrow$ \\
\hline & $\mathrm{TP}$ & $\mathrm{AM}$ & 100 & 102.1 & 98.8 & 98.5 & 96.4 \\
\hline & & ASD & 0 & 1.4 & 2.1 & 3.3 & 3.8 \\
\hline & & $p^{\mathrm{b}}$ & & $\mathrm{ns}$ & $\mathrm{ns}$ & ns & $\mathrm{ns}$ \\
\hline & ST & $\mathrm{AM}$ & 100 & 88.4 & 82.2 & 81.1 & 78.2 \\
\hline & & ASD & 0 & 2.6 & 0.4 & 2.6 & 0.5 \\
\hline & & $p^{\mathrm{b}}$ & & $\downarrow$ & $\downarrow$ & $\downarrow$ & $\downarrow$ \\
\hline
\end{tabular}

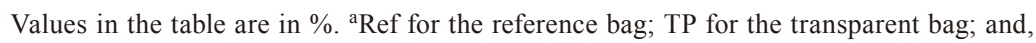
ST for the semi-transparent bag. For details, see the Materials and Methods section. ${ }^{\mathrm{b}} \mathrm{Com}-$ parison with the $0 \mathrm{~h}$ value (See the Statistical analysis section). The downward arrow shows a significant decrease $(p<0.05)$. ns stands for $p \geq 0.05$. 
Table 2. Comparison of three types of bags on solvent vapor retention

\begin{tabular}{|c|c|c|c|c|c|c|c|}
\hline \multirow{2}{*}{\multicolumn{2}{|c|}{ Organic solvent }} & \multirow{3}{*}{$\begin{array}{c}\begin{array}{c}p \text { by G-G } \\
\text { test }^{\mathrm{a}}\end{array} \\
<0.001\end{array}$} & \multirow{3}{*}{$\begin{array}{c}\text { Two bags }{ }^{\mathrm{b}} \text { to be } \\
\text { compared } \\
\text { Ref vs. TP }\end{array}$} & \multicolumn{4}{|c|}{ Duration of storage $(\mathrm{h})$} \\
\hline & & & & \multirow{2}{*}{$\begin{array}{l}12 \\
<\end{array}$} & \multirow{2}{*}{$\begin{array}{l}24 \\
=\end{array}$} & \multirow{2}{*}{$\begin{array}{l}36 \\
=\end{array}$} & \multirow{2}{*}{$\begin{array}{l}48 \\
=\end{array}$} \\
\hline Group 1 & Ethyl acetate & & & & & & \\
\hline & & & Ref vs. ST & $>$ & $>$ & $>$ & $>$ \\
\hline & & & TP vs. ST & $>$ & $>$ & $>$ & $>$ \\
\hline & Toluene & 0.0173 & Ref vs. TP & $<$ & $<$ & $<$ & $<$ \\
\hline & & & Ref vs. ST & $=$ & $=$ & $=$ & $=$ \\
\hline & & & TP vs. ST & $=$ & $>$ & $>$ & $>$ \\
\hline \multirow[t]{9}{*}{ Group 2} & Isopropyl alcohol & 0.0473 & Ref vs. TP & $=$ & $=$ & $=$ & $=$ \\
\hline & & & Ref vs. ST & $>$ & $>$ & $>$ & $=$ \\
\hline & & & TP vs. ST & $>$ & $>$ & $>$ & $>$ \\
\hline & Chloroform & 0.0007 & Ref vs. TP & $=$ & $=$ & $=$ & $=$ \\
\hline & & & Ref vs. ST & $=$ & $=$ & $=$ & $<$ \\
\hline & & & TP vs. ST & $=$ & $=$ & $<$ & $<$ \\
\hline & Butyl acetate & $<0.001$ & Ref vs. TP & $=$ & $<$ & $<$ & $<$ \\
\hline & & & Ref vs. ST & $>$ & $>$ & $>$ & $>$ \\
\hline & & & TP vs. ST & $>$ & $>$ & $>$ & $>$ \\
\hline
\end{tabular}

$>$ indicates that the bag on the left showed better retention than the bag on the right. $<$ showes that the reverse was the acse. $=$ shows no difference. $p<0.05$ was taken as the cut-off. See Table 1 for measured value in percentage. ${ }^{a}$ Greenhouse-Geisser test. ${ }^{b}$ Ref for the reference bag; TP for the transparent bag; and ST for the semi-transparent bag. For details, see the Materials and Methods section.

\section{References}

1) Nagasawa $Y$, Ukai U, Okamoto S, Samoto H, Itoh K, Moriguchi J, Sakagami S, Ohashi F, Takaka S, Kawakami T, Ikeda M (2011) Organic solvent use in enterprises in Japan. Ind Health 49, 534-41. [Medline] [CrossRef]

2) Nagasawa $Y$, Ukai U, Okamoto S, Samoto H, Itoh K, Moriguchi J, Sakagami S, Ohashi F, Takaka S, Kawakami T, Ikeda M (2011) Organic solvent use in research institutions in Japan. Ind Health 49, 421-6. [Medline] [CrossRef]

3) Ministry of Health, Labour and Welfare, Japan (2006) Work Environment Evaluation Standards (Ministry of Health, Labour and Welfare Notification No. 50; originally enacted in 1988 as Ministry of Health, Labour and Welfare Notification No. 79). Tokyo (in Japanese).

4) Tanaka S (2009) New sampling bags FlexFilm and FlexFoil. Proceedings of the Joint Conference of the 49th Annual Meeting of Japan Occupational Hygiene Association and the 30th Annual Meeting of Japan Association of Working Environment Measurement. 71-72 (in Japanese).

5) Groves WA, Zellers ET, Edward T (1996) Investigation of organic vapor losses to condensed water in Tedlar bags used for exhaled-breath sampling. Am Ind Hyg Assoc J 57, 257-63. [Medline] [CrossRef]

6) Kim YH, Kim KH, Jo SH, Jeon EC, Sohn JR, Parker DB (2012) Comparison of storage stability of odorous VOCs in polyester aluminum and polyvinyl fluoride Tedlar ${ }^{\circledR}$ bags. Anal Chim Acta 712, 162-7. [Medline] [CrossRef]
7) Kudo M, Kimura J (1981) Retention of organic solvent vapors in plastic bags (Part 5). Sangyo Igaku 23, 612-8 (in Japanese with English abstract). [Medline] [CrossRef]

8) Kudo M, Tanabe N, Kimura J (1979) Retention of organic solvent vapors in plastic bags (Part 1). Sangyo Igaku 21, 552-3 (in Japanese). [Medline] [CrossRef]

9) Kudo M, Tanaka N, Kimura J (1980) Retention of organic solvent vapors in plastic bags (Part 2). Sangyo Igaku 22, 278-9 (in Japanese). [Medline] [CrossRef]

10) Kudo M, Tanaka N, Kimura J (1980) Retention of organic solvent vapors in plastic bags (Part 3). Sangyo Igaku 22, 386-7 (in Japanese). [Medline] [CrossRef]

11) Kudo M, Tanaka N, Kimura J (1981) Retention of organic solvent vapors in plastic bags (Part 4). Sangyo Igaku 23, 170-1 (in Japanese). [Medline] [CrossRef]

12) Tsuchihana $Y$, Ashida T, Koike S (1983) Performance of air-sampling bags for measurement of organic solvent vapor concentration. Yobo-igaku (Prev Med) 25, 98-203 (in Japanese).

13) Iwamoto A (2010) A new sampling bag made of polyester. Proceedings of the Joint Conference of the 50th Annual Meeting of Japan Occupational Hygiene Association and the 31st Annual Meeting of Japan Association of Working Environment Measurement. 54-55 (in Japanese).

14) Yano C, Hinoue M, Yoshikawa M (2011) Time-dependent decay of methanol and other organic solvents in Tedlar bag. Proceedings of the Joint Conference of the 51st Annual Meeting of Japan Occupational Hygiene Association and the 32nd Annual Meeting of Japan Association of Working 
Environment Measurement. 160-161 (in Japanese).

15) Yoneyama R, Takeuchi Y, Kishida T (2011) Selection of air sampling bags made of new materials. Proceedings of the Joint Conference of the 51st Annual Meeting of Japan
Occupational Hygiene Association and the 32nd Annual Meeting of Japan Association of Working Environment Measurement. 158-159 (in Japanese). 